\title{
Integral Architecture for Organizational Systems Arquetipos
}

\author{
Ana Milena Páez Quintero ${ }^{1 *}$, Ricardo Llamosa Villalba², Edgar Sneyder García Morantes ${ }^{2}$ \\ ${ }^{1}$ Innovation and Development Center for Software Engineering Research -CIDLIS-, Universidad Industrial de \\ Santander -UIS-, Cra 27 calle 9, Bucaramanga, Santander, Colombia. \\ 2 Electrical, Electronics and Telecomunication Engineering School, Universidad Industrial de Santander -UIS-, Cra \\ 27 calle 9, Bucaramanga, Santander, Colombia.
}

* Corresponding author. Tel: +57 3174973061; email: ANA.PAEZ@correo.uis.edu.co.

Manuscript submitted January 16, 2015; accepted March 3, 2015.

doi: 10.17706/jsw.10.3.366-373

\begin{abstract}
ARQUETIPOS is a meta-model that combines structural elements given by TOGAF, Enterprise Architecture, agile methods and ZACHMAN frameworks, with prototyping and simulation techniques. There are advantages to this model such as its iterative approach, which grants real-time results to stakeholders. Also, when using this model, requirements and solutions evolve through the collaboration of high performance teams. From an ontological approach ARQUETIPOS is composed of five components: The Framework for Capability, the Content of the Architecture, the Implementation Method, the Maturity Assessment Model of Organizational Systems and the Meta-model Repository. This paper aims to test the implementation of ARQUETIPOS in the education and productive sector through the use of agile principles and prototyping and simulation techniques. The techniques or strategies used to implement this meta-model are varied, in this case the training service was used. This strategy allowed the main actors in this paper (Academia and companies) to model their organizational processes through the creation of prototypes with Lego. In consequence, that let them to get better services and products aligned with their business strategy.
\end{abstract}

Key words: Agile principles, enterprise architecture, prototyping and simulation techniques.

\section{Introduction}

Enterprise Architecture (EA) has become a valuable tool for strategic planning and the alignment of the business vision in the Information and technology organizations. Different international frameworks have been established to bring together practices in order to define and implement the EA. EA requires identifying certain approaches which provide a context for organizational modeling. However, the approaches suggested in each specific methodology do not integrate all organizational aspects that can be observed in the structure of a business. The existing frameworks focus their attention on a particular aspect of the organizational environment. Therefore, the suggested approaches are specific and bound to a precise feature.

ARQUETIPOS contains in its methodology of implementation the principles of the Agile Manifesto [1]: "Individuals and interactions over processes and tools", "Working systems over comprehensive documentation", "Customer collaboration over contract negotiation" and "Responding to change over following a plan". Furthermore, ARQUETIPOS includes prototyping and simulation techniques, which deliver betas to the stakeholders in each iteration.

From the integration of agile principles, simulation and prototyping techniques, and concepts of integrated Enterprise Architectures, this paper proposes a meta-model. The meta-model intends to structure, organize, design and implement an organizational architecture in a system. Additionally, it looks for answering the 
following questions:

- Is it possible to design an enterprise architecture that contains approaches related to business processes, training of human resources and assessments methods of the architecture?

- How to achieve a comprehensive modeling of an organization through Enterprise Architectures, which are defined by approaches, as communication as a critical factor of success?

- How to transfer, adapt and implement organizational systems architecture in a company according its business objectives?

\section{Arquetipos Meta-Model}

ARQUETIPOS is a meta-model proposed by the CIDLIS research group, under the parameters given by the TOGAF [2], Zachman [3] and agile methods [4] framework. It is composed of models, techniques and supporting tools that are useful for developing enterprise architecture from different archetypes of organizational systems, including: education, government and enterprises and, approached from three functional dimensions: Ontological, Epistemological and Methodological.

Within a static perspective, the ontological meta-model dimension defines the structural view of the architecture, enabling the organization to study and analyze how their organizational entities interact. From a dynamic perspective, the epistemological dimension provides the knowledge to take decisions in the organization, adding value to the business strategy. This knowledge is given when relevant information is measured and evaluated in the architecture. Finally, the methodological dimension relates the ontological and epistemological dimensions in order to find the set of procedures used to achieve organizational goals through the definition of enterprise architecture.

The meta-model is structured into five parts: The Framework for Capability FCA, which helps to define the organization, roles, abilities and responsibilities required to operate; the Content of the Architecture COA, which establishes the architectural structures of the artifacts and deliverables and, the reusability of the building blocks; the Implementation Method MIA, which defines how to develop an enterprise architecture in an organizational system; the Maturity Assessment Model of Organizational Systems MEMORIA and, the Meta-model Repository RCA, which is categorized according to the guidelines given by enterprise architecture [5].

\subsection{Arquetipos Implementation Method MIA}

The Implementation Method MIA proposes the use of the agile methods principles and guidelines, in order to implement designing activities and to develop the Enterprise Architecture (EA). All this, around defined goals, with optimal performance and efficiency standards and supported by the Agile Manifesto principles [1]:

- Stakeholders and project managers in an EA must work together, daily, during the EA design and implementation.

- EA is developed around motivated human resources. For that reason, motivation and confidence to carry out their job are given to each participant. In other words, this is associated with high performing teams.

- Added value is the main measure of progress in EA.

- Agile processes promote the steady delivery of value. For this, human resources must keep a constant rate of work during the EA project execution.

- Continuous attention to technical excellence enhances project agility.

- Project teams are self-organized and self-managed.

- At regular intervals, the team reflects on how to become more effective, and then adjusts its behaviours accordingly.

Fig. 1 shows the MIA organizational structure, phases and processes. It is worth noting, that before the onset of EA implementation, feasibility, initiation and delivery planning phases must be run, and through this the basic guidelines of the project are defined. Then, the implementation of the iterations phase is carried out. During this phase, a five-step iteration process occurs: First, the iteration is planned. Then, the EA is projected, in which, the 
architectural requirements, the EA project backlog and the product or architectural content backlog are reviewed. After that, the EA is designed, implemented and delivered. Lastly, no development requirements are reviewed to mount the next iteration and learned lessons are identified.

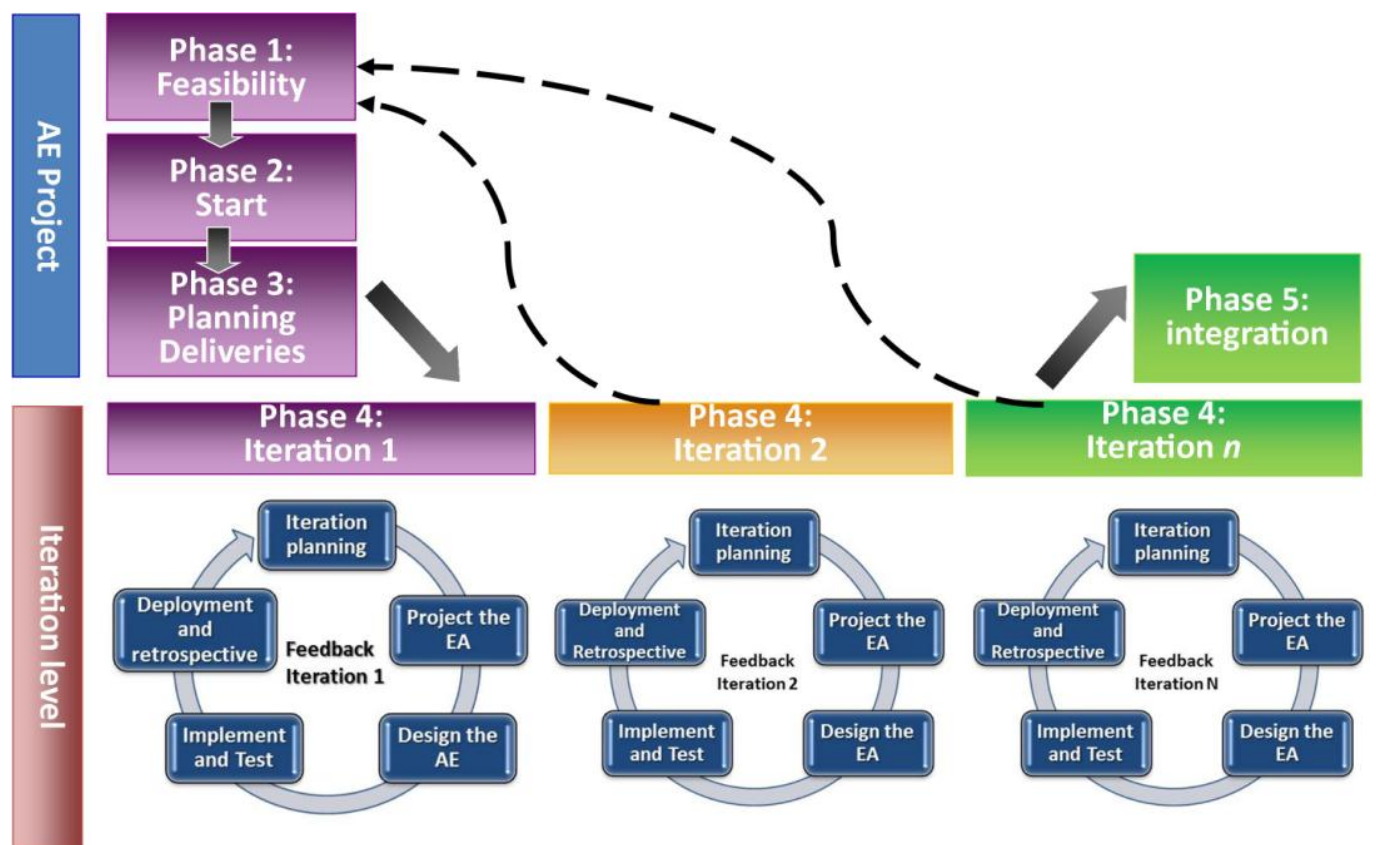

Fig. 1. MIA organizational structure, phases and process.

ARQUETIPOS argues that prior to the deployment of the architectural solutions in the organization, it's necessary to design, implement and test the architectural prototypes with the EA work package, through physical or digital simulation, or a physical or digital prototype (demo). The demo can generate any of the following products: work timetables, organizational blueprints or models, simulations of production lines or service lines, manual processes, systemized or automated processes, information systems, databases, networks, application interfaces (technology services), and others.

\subsection{Arquetipos Content of the Architecture -COA-}

ARQUETIPOS meta-model establishes the structural organization of products and deliverables within its content, thereby generating a set of architectural components that can be accessed by the different stakeholders in the organization. Fig. 2, shows one of the more important content meta-model benefits, that is, its organization in architectural categories (columns) and abstraction levels (rows), as well as, the support to the traceability among components [6]. ARQUETIPOS Content of the Architecture is based on the defined TOGAF and ZACHMAN framework. TOGAF defines a structure for the content from different points of view: Business Architecture, Technology Architecture and Information Architecture. Therefore, ARQUETIPOS adds two points of view: the Event Architecture, When? And the Communication Architecture, Who?

Also, ARQUETIPOS adopts TOGAF framework to classify its contents as: Deliverables, which represent the EA project outputs, generally, they are contractually defined and reviewed on a document delivered to the stakeholder. Artifacts or the EA work products, which include catalogs, matrixes, diagrams, prototypes and simulations. And, Building Blocks, which represent the organizational enterprise capacity, they are potentially reusable in other architectures. For example, a document with the definition of the Technological Architecture is a deliverable; building blocks could be the diagrams that explain the mobile device communication network of the organization. When these diagrams are reused by other architectures, they become building blocks. The added value of ARQUETIPOS is that through the implementation method MIA, it can define how to transform an existing architecture into target architecture through identifying the gaps. 


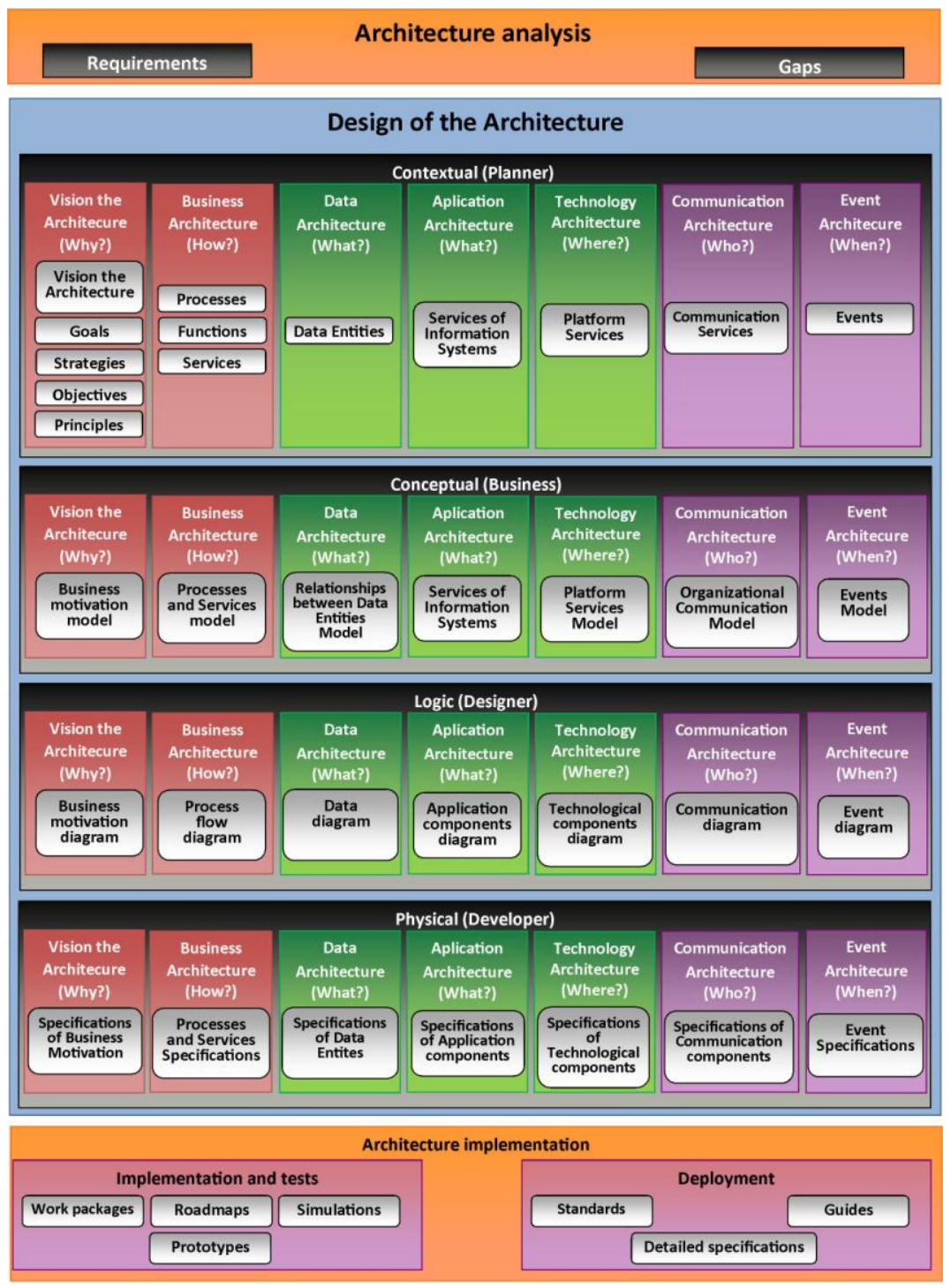

Fig. 2. ARQUETIPOS content of the architecture -COA-.

\subsection{Arquetipos Framework for Capability Model -FAC-}

ARQUETIPOS Capability Model consists of a set of organizational structures such as processes, roles, responsibilities and required skills, in order to put the organizational architecture capacity into operation. Also, FCA defines the elements and the necessary resources to ensure the effectiveness of the implementation of the architecture within the organization [7].

There are three components that form the basis of the ARQUETIPOS capability, which are:

- ARQUETIPOS governance model: The governance model established in ARQUETIPOS is responsible for defining the structure, the activities and the processes that regulate and direct the architecture in the organization.

- Processes and principles formal model: The formal processes of the organizational architecture are related with the POLO model and the MIA method. As a consequence, they guide, inform and support the way in which an organization fulfills its mission through the use of technologies and information. The Table 1, shows the POLO model, which becomes the framework for the business processes and the organizational architecture. That means that companies can use the processes practices defined in POLO, in order to make their own processes for the implementation of the enterprise architecture.

- ARQUETIPOS conformity model: The conformity model is a strategy that ensures compliance with the organizational architecture. This model is associated with the assessment, monitoring and supervising 
techniques and tools.

Table 1. List of Practices of Organizational Leadership Process Model POLO

\begin{tabular}{|c|c|c|}
\hline The practices of the processes & No. & Description \\
\hline \multirow{11}{*}{$\begin{array}{l}\text { Administrative } \\
\text { Management }\end{array}$} & 1. & Analysis and Making Decisions \\
\hline & 2. & Analysis Causes \\
\hline & 3. & Strategic Management of Organizational Processes \\
\hline & 4. & Requirements Management \\
\hline & 5. & Planning of Organizational Processes \\
\hline & 6. & Monitoring and Control of Organizational Processes \\
\hline & 7. & Risks Management \\
\hline & 8. & Quantitative Management of Organizational Processes \\
\hline & 9. & Financial Management \\
\hline & 10. & Capacity and Availability Administration \\
\hline & 11. & Agreements with Suppliers Management \\
\hline \multirow{8}{*}{$\begin{array}{c}\text { Operational } \\
\text { Management }\end{array}$} & 12. & Requirements Definition \\
\hline & 13. & Design and Development of Organizational Products and Services \\
\hline & 14. & Verification of Products and Services \\
\hline & 15. & Validation of Products and Services \\
\hline & 16. & Provide Organizational Services \\
\hline & 17. & Continuity of Organizational Services \\
\hline & 18. & Prevention and Management of Incidents \\
\hline & 19. & Transition of Service \\
\hline \multirow{7}{*}{ Management Tactics } & 20. & Configuration Management of Knowledge Assets \\
\hline & 21. & Analysis and Measurement \\
\hline & 22. & Assuring the Quality \\
\hline & 23. & Organizational Training \\
\hline & 24. & Communications Management \\
\hline & 25. & Performance Measurement of Organizational Process \\
\hline & 26. & Organizational Intelligence \\
\hline \multirow{2}{*}{ Strategic Management } & 27. & Definition and Improvement of processes \\
\hline & 28. & Investigation, Development and Innovation \\
\hline
\end{tabular}

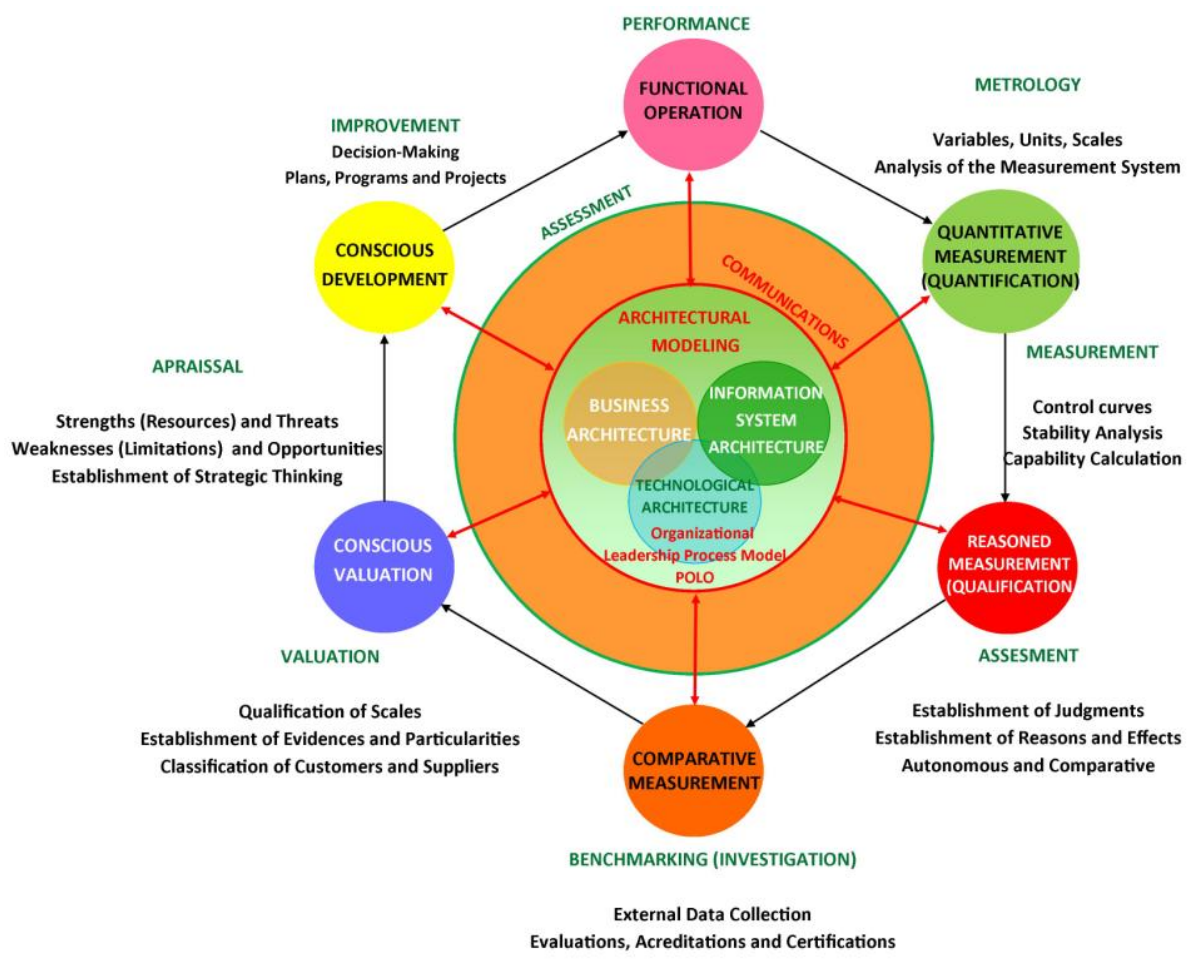

Fig. 3. Maturity assessment model of organizational systems MEMORIA. 


\subsection{Maturity Assessment Model of Organizational Systems -MEMORIA-}

Fig. 3 shows MEMORIA model. MEMORIA aims at assessing the processes and improving the capacity of the organizational systems. So, in order to fulfill its purpose, the model provides different techniques and assessment tools to review the operation of the organizational architecture as well as make comparisons with standards and patterns through the collaborative work of all participants.

MEMORIA gathers a systematic method for the evaluation of the organizational systems maturity. For that reason, this article proposes it as a tool to evaluate the organizational architecture operation [5], in order to obtain possible benefits such as: Identify metrics to establish a system for measuring the performance of the organizational architecture; realize quantitative measurements by collecting information using quantitative tools for this activity; realize qualitative measurements based on estimates from the data collected for the establishment of judgments, reasons and effects of causal relationship between variables; study the environment, to perform benchmarking on key standards, patterns or models in relation to the projects and the EA processes; conduct assessments from the evidence using predefined scales qualification, this evaluation includes rating the content and enterprise architectures processes using evaluation rubrics and defining scales for each criterion and realize a valuation of the Weaknesses, Opportunities, Strengths and Threats DOFA, in order to establish the strategic thinking around the enterprise architecture processes.

\section{Results}

During the implementation of the MIA methodology in order to design the enterprise architecture for the CIDLIS research group, it was noted that:

- It's important to define a government model and to set a work team aligned with the managers of the organization in order to establish the vision and architecture of the business.

- Also, it's important to define the business strategy first, as a basis for all other architecture components, such as Events architecture, Communications architecture, Information architecture and Technology architecture.

- Furthermore, it's necessary to identify the current architecture and the target architecture in order to determine the gaps. This leads to the establishment of a roadmap for the implementation of the architecture.

- Moreover, the instruments defined to design the organizational architecture must be flexible.

- Lastly, daily releases are important because the architecture is supported by a committed and motivated, high performance team.

\subsection{Arquetipos Education Sector}

The first piloting experience of agile school. It was developed in both, the probability and statistics course and the quality engineering course within the Electric, Electronic and Telecommunication School -E3T- at Universidad Industrial de Santander in 2013. This piloting experience was based on MEMORIA_PE project [8]. And, the following ARQUETIPOS models were applied: POLO framework, which organized the teaching-learning practices in the following categories: Administrative Management, Tactical Administration, Strategic Management and Operative Management. The business architecture of the courses was defined on this basis; MEMORIA model, which defined the maturity levels for each educational process. It was also used for the evaluation the educational practices; prototyping and Simulation techniques, through the use of educational resources and strategies, such as: Learning method based on Serious Play, Lean Startup, and other techniques and the Agile Methods techniques in the implementation of the courses, especially in teaching, learning and assessment practices.

\subsection{Arquetipos in Business Sector}

In the productive sector entities ARQUETIPOS was applied using an innovative strategy based on building 
workshops known as Enterprise Architectures with Agile Methods ARTEMA was implemented. The workshop aimed at establishing in real-time an approach to the business processes and its architecture through the use of LEGO SERIOUS PLAY method as a technique for simulation and prototyping. Approximately ten people from different areas or departments took part of the workshop. The activity included three moments: in the first moment, the perspective and the structure of the high-performance work teams in the organization were defined, in the second moment, under the perspective of an integral architecture, the processes of the organization were modeled. Lastly, in the third moment, the development plans of the activities for the organizational leadership were elaborated.

\subsection{Arquetipos at Universidad Industrial de Santander}

ARQUETIPOS was implemented through a workshop delivered to the school faculty in the Electrical, Electronics and Telecommunication Engineering School E3T at Universidad Industrial de Santander. Professors were encouraged to establishing a real-time approach to the business processes and their architecture through the use of LEGO SERIOUS PLAY method as a technique for simulation and prototyping.

\section{Conclusion}

ARQUETIPOS has become a reference framework that allows organizations to improve and optimize its missional processes through the use of models, techniques, tools and the best practices of process, products and services or business models provided by POLO and MEMORIA and supported by information and communication technologies. There are many ways to implement the meta-model. In this case, the ARTEMA service training called Organizational Systems Laboratory LASIO [9] was used. The purpose of that workshop was that academics and business managers could make a model of their organizational processes. As a result of that, they obtained better services or products that were aligned with their business strategy and, integrated with their strategic, administrative, tactical and operational model.

\section{Acknowledgment}

Thanks to CIDLIS research group, to Colciencias and to the Universidad Industrial de Santander, for their significant contribution in human and economic resources to the development of the project of Young Researchers 2014. Also, we thank the research guidance provided for the scientific director of CIDLIS research group Dr. Ricardo Llamosa Villalba in this research work.

\section{References}

[1] Beck, K., Beedle, M., Cockburn, W., Fowler, M., Greenning, J., Hunt, A. et al. (2001). Manifesto for Agile Software Development. Retrieved February 12, 2013, from website: http://agilemanifesto.org/

[2] The open group. (1995-2014). Enterprise Edition Version 9.1. Retrieved December 20, 2013, from website: http://www.opengroup.org/togaf/.

[3] Zachman, J. P. (2009-2011). The zachman framework evolution: Zachman international enterprise architecture. Retrieved November 8, 2013, from: http://www.zachman.com/ea-articles-reference/54-the-zachman-framework-evolution

[4] Bente, S., Bombosch, U., \& Langade, S. (2012). Collaborative Enterprise Architecture: Enriching EA with Lean, Agile, and Enterprise 2.0 practices. Morgan Kaufmann.

[5] CIDLIS research group. (2013). Maturity Assessment Model of Organizational Systems -MEMORIA-, Bucaramanga: Universidad Industrial de Santander.

[6] CIDLIS research group. (2013). Content ARQUETIPOS - COA -. Bucaramanga: Universidad Industrial de Santander.

[7] CIDLIS research group. (2013). Capability Framework ARQUETIPOS - FCA -. Bucaramanga: Universidad Industrial de Santander.

[8] CIDLIS research group. (2012). Maturity Model of Educational Processes -MEMORIA_PE-. Bucaramanga: 
Universidad Industrial de Santander.

[9] CIDLIS research group. (2013). Organizational Systems Laboratory LASIO. Bucaramanga: Universidad Industrial de Santander.

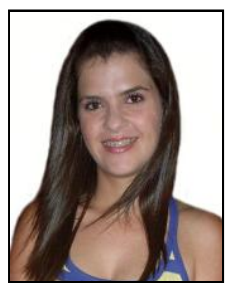

Ana Milena Páez Quintero was born in Ocaña, Norte de Santander, Colombia in 1988. She received her B.S. degree in systems engineering from the Universidad Industrial de Santander, Bucaramanga, Colombia in 2012.

Currently, she works as a young researcher in the research group CIDLIS that belongs to the Universidad Industrial de Santander, Bucaramanga, Colombia. Her current research interests include agile methods in education, enterprise architectures, software engineering, business architecture, project managements, and business management.

Ms. Paéz was favored with the 2014 Young Researcher scholarship awarded by the Department Administrative de Ciencia, Tecnología e Innovación (Colciencias) in Colombia.

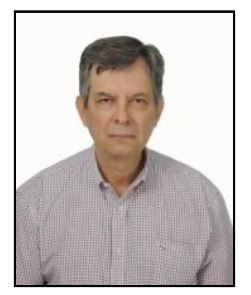

Ricardo Llamosa Villalba was born in Bogotá, Cundinamarca, Colombia in 1950. He received hisPh.D. and M. S. degree in telecommunications from the Universidad Politécnica de Madrid, Madrid, Spain in 1987, and the B. S. degree in systems engineering from the Universidad Industrial de Santander, Bucaramanga, Colombia in 1975

In 1991, he created the research group CIDLIS at Universidad Industrial de Santander. Since 2000, he has been working as laureate the head teacher of the school of electrical, electronics and telecommunications engineering that belongs to the Universidad Industrial de Santander, Bucaramanga, Colombia. His current research interests include software engineering, quality in the processes and risk management in the processes.

Dr. Llamosa is certified in the Governance of Enterprise IT, Risk and Information System, and Project Manager Professional. In addition, he is the founder and editor of the journal Gerencia Tecnológica Informática (ISSN: 1657-8236). He was part of the evaluation committee on the IEEE International Conference on Teaching, Assessment and Learning for Engineering TALE 2013, Kuta, Indonesia.,

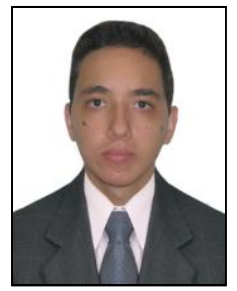

Edgar Sneyder García Morantes was born in Bucaramanga, Santander, Colombia in 1991. He received his B.S. degree in electronic engineering from the Universidad Industrial de Santander, Bucaramanga, Colombia in 2013.

Currently, he works as a young researcher in the research group CIDLIS that belongs to the Universidad Industrial de Santander, Bucaramanga, Colombia. His current research interests include agile methods, enterprise architectures, optimization methods, statistical signal processing, control of dynamical systems and automatization.

Mr. García was favored with the 2014 Young Researcher scholarship awarded by the Department Administrative de Ciencia, Tecnología e Innovación (Colciencias) in Colombia. 